\title{
Scenario and Strategy towards Energy Efficiency in Malaysia: A Review
}

\author{
Nurul Asra Abd Rahman ${ }^{1,2 *}$, Syahrul Nizam Kamaruzzaman ${ }^{1}$, and Farid Wajdi Akashah ${ }^{1}$ \\ ${ }^{1}$ Faculty of Built Environment, Universiti Malaya, 50603 Kuala Lumpur, Malaysia, \\ ${ }^{2}$ Faculty of Architecture, Planning and Surveying, Universiti Teknologi MARA, Shah Alam.
}

\begin{abstract}
Malaysia is among the highest consumers in term of consumption and intensity of energy per capita in Asia. Malaysia's final energy consumption had increased from 13 million toe in 1990 to about 41 million toe in 2010, reflecting an annual average growth rate of $6 \%$. Despites aggressive energy efficiency drives implemented for last 20 years, Malaysia has not shown any improvement in term of energy consumption and conservation. The Lower than anticipated results under previous energy efficiency initiatives had forced The Malaysian government to launch National Energy Efficiency Action Plan for 10 year implementation period of 2016-2025 (NEEAP) after taking into account the socio-culture, policy, financial, and administration barriers. The objective of this paper is to review Malaysian experience in their energy efficiency initiatives in comparison with other leading nations. Study reveals that overlapping and interchangeable terms for energy efficiency, energy conservation and renewable energy approaches under NEEAP causes confusion during implementation and monitoring which raise the need for reinterpretation of the programme initiatives. The barriers are not only isolated for Malaysian context but also common problems experienced by other countries. This offer opportunities for leapfrogging and knowledge sharing for improving any possible measures under three major initiatives for equipment, industrial and building programmes as outlined under the NEEAP. Some suggestions are made in this paper as measures to improve the delivery mechanism.
\end{abstract}

\section{Introduction}

Under Malaysia energy policies the terms energy efficiency, energy conservation and renewable energy (RE) are often interchangeable. They share the same goal and objective to reduce demand for energy, to safeguard the fast depleting natural fossil fuel resources and to protect the environment from harmful carbon emission.

Energy efficiency is the objectives to decrease the quantum of energy needed to deliver products and services. On the other hand, energy conservation is the endeavour made to decrease energy usage by using less energy services [1]. The differences between the two terms is that energy efficiency is adopting technologies that consume less energy to achieve the same functional parameters, whereby you do not have to change your behaviour or sacrifice comfort to save energy. Energy conservation is any behaviour that can produce positive outcome in reducing energy consumption or compromising on certain services to save energy [2]. Globally too much emphasis had been given towards highly technical and costly energy efficiency drives that basic approach for energy conservation that require less investment is often neglected. The Malaysian government need to consider giving these two approaches equal footings in order to see quicker energy saving result.

The complexity of relationship between improvement of energy efficiency and the utilisation of renewable energy technologies is widely reported. However, if the potentials of both programmes are combined the world energy demand can be reduced around $25 \%$ by 2030 . Energy savings from renewable is estimated to be a quarter from total energy demand while energy efficiency measures delivering the rest. Therefore, meeting the objectives of renewable energy can contribute towards the success of energy efficiency measures in reducing global energy demand [3].

\section{Energy Consumption}

Suruhanjaya Tenaga (ST) which started operation in January 2002 is responsible for regulating the energy sector in Malaysia in ensuring reliable electricity and gas supply at reasonable cost as required by all sectors such as industrial, commercial, transportation, communication and residential [4]. Having dependent mainly on oil and gas generated power plants for half a century, Malaysia had realised the importance of adopting renewable energy as an alternative to conventional non-renewable energy resources and continuously reviewed its energy

\footnotetext{
Corresponding author: mynurulasra@gmail.com
} 
policy to ensure sustainable energy supply and security. Fast depleting non-renewable fossil fuel energy resources that is detrimental to the environment had also raises awareness for a more sustainable energy efficiency measures to use renewable energy resources, to reduce demand for energy development which are contributing towards the positive economic, social and environmental development.

Global statistic indicated that as a result of energy efficiency initiatives, the world power consumption was reduced by $1.5 \%$ in 2009 for the first time since World War 2. Unfortunately, Asian and Middle Eastern countries despites softening effect still recorded an increase in power consumption due to rapid development [5].

Statistic by Suruhanjaya Tenaga indicated that Malaysia is among the highest in term of consumption and intensity of energy per capita in Asia. The annual growth rate of Malaysia final energy consumption stands at $6 \%$ based for a 20 years period. 13 million toe of energy was used in 1990 and increased to 41 million toe in 2010. The annual growth rate electricity consumption during the same period stands at $9 \%$ while the GDP annual growth rate stands at only $6 \%$ [6]. This was despites after Malaysia embarked on various sustainable energy efficiency, energy conservation and renewable energy measures.

Based on 2008 statistics, the total energy consumption was 44,901 ktoe and the distribution for energy consumption among various resources in descending order are: petroleum products at $54.4 \%$, gas at $23.9 \%$, electricity at $17.8 \%$ and coal/coke at 3.8 . The energy consumption among different sectors in 2008 in descending order are: industrial sector at $42.6 \%$ with 18,667 ktoe, transportation sector at $36.9 \%$ with 16,395 ktoe, commercial and residential sectors at $13.8 \%$ with 6,205 ktoe and other sectors (agriculture and non-energy form the remaining with 3,163 ktoe. The energy consumption by the industrial sector and transportation sector combined already utilised $75.5 \%$ of the total energy resources [7].

A study on energy consumption and energy intensity for large office buildings in Malaysia reveals that among different electrical services, air conditioners are the major energy users $(57 \%)$, followed by lighting $(19 \%)$, lifts and pumps (18\%) and other equipment (6\%). Similar statistics on other sector and building typologies may show slightly different patterns of power consumption distribution. These types of statistics may help the policy maker and energy players drafting accurate energy efficiency initiatives [8].

\section{Energy Efficiency \& Conservation}

There are several benefits for implementation of energy efficiency programmes especially when energy-efficient technologies are used. It may drastically reduce energy consumption and translate to financial cost saving after off-set from the initial investment cost. Other than monetary issues, energy saving may also contribute towards protecting the environment through reduction of greenhouse gas emission [9].

The government policies, initiatives and programmes for energy efficiency and energy conservation have seen some improvement for the last 10 years. Unfortunately the uptake is still low and the economic potential has not been fully exploited. This is despites the vital role and benefits it can play in cutting energy demand. Therefore, the government need to improve the delivery mechanism by adopting more energy efficient technologies in various sectors. Based on experiences by developed nations, it is proven that energy can be conserved by reducing wastage and losses, improving efficiency through technological upgrades and improved operation and maintenance [10]. Energy conservation being the top of sustainable energy hierarchy is part of the concept of eco-sufficiency that reduces the need for energy services which in turn promotes environmental quality, national security, personal financial security and higher savings. Essentially, it also lowers energy costs by preventing future resource depletion.

Self-sufficient solar house is found to be less energy efficient than an equivalent passive solar house since the passive house can decrease life cycle energy demand by a factor of three [11]. Use of passive design combined with active technologies can reduce building's energy life cycle energy demand significantly as compared to fully self-sufficient zero rated passive building. It is observed that low energy buildings perform better than self-sufficient (zero operating energy) buildings in the life cycle context.

\section{Energy Efficiency \& Conservation barriers and challenges}

Ministry of green energy and Water (KETTHA) had identified and analysed the barriers and challenges encountered by the energy industry for the implementation of energy efficiency initiatives up until 2015. Among the key challenges identified includes [12]:

1) Socio-culture barrier: Energy efficiency investments are not attractive since the returns in terms of energy savings are small due to the low energy prices.

2) Financial Barrier: Dedicated finance scheme for energy efficiency from commercial lending institutions has been difficult to obtain, as the banks have not built sufficient capacity to deal with energy efficiency project evaluation and project finance schemes.

3) Policy barrier: Lack of overall national plan for energy efficiency without any underlying road map or action plan for the implementation. The activities are poorly coordinated covers mostly individual short-term projects without clear medium term and long-term objective. 
4) Administrative barrier: It encompasses political, institutional and regulatory conditions. No clear authority in charge of ensuring energy efficiency holistic programmes is properly map out and coordinated. The planning is still very much based on demand forecast and supply planning, without taking into account energy efficiency and demand side management.

Lack of consistency in promoting and embarking on the energy efficiency since most programmes are projects-based run on limited budget allocation with short time frame.

Industrialized nation like China continue to focus on improving energy efficiency in the industry sector for being the highest consumer of energy. Policies and regulations are instrumental towards energy efficiency drives despite the aspiration to use more economic model. The success rate of energy efficiency initiatives is moderate and fail to create any major paradigm shift towards the energy sector. Rational fine tuning was introduced to the incentives with modifications to the allocation of targets, the frequency of assessment and the eligibility of subsidies. This proves that the energy efficiency action plans should be flexible enough to adopt any changes to overcome any obstacles along the way. [13].

\section{Renewable Energy barriers \& Challenges}

REN21's 2017 report indicated that renewable energy contributed $19.3 \%$ of humans' global energy supply and generation of electricity in 2015. The percentile increased to $24.5 \%$ in 2016 with a net increase of $5.2 \%$. The distribution of renewable resources for electricity generation mainly comes from traditional biomass at $8.9 \%$, heat energy (modern biomass, geothermal \& solar) at $4.2 \%, \%$, hydro electricity at $3.9 \%$ and wind at $2.2 \%$. [14].

Biomass, solar and hydro are among the renewable energy resources naturally available in abundance in Malaysia. Realising the potential, policies and regulations for development of renewable energy as the $5^{\text {th }}$ fuel strategy in the energy-mix have been drafted under National Energy Policy (NEP) in 2001. Small energy power program (SREP) was launched at the same time and it comes with fiscal incentives to promote renewable energy initiative. Unfortunately, initiatives under SREP produced unfavourable result whereby the initial target of $500 \mathrm{MW}$ grid-connected renewable power generation with 2005 deadline was extended to 2006. Due to several barriers and challenges the target was downgraded to $350 \mathrm{MW}$ with an extended deadline until 2010 [15].

The decade old renewable energy policy has since been revised and upgraded to get better power generation output from renewable resources. This was done to capitalise on the potential of increasing renewable energy, reducing energy consumption without impending economic growth and productivity. In doing so, the government has identified the barriers in RE initiatives;

Financial barriers: The current business environment with lack of experience and suitable support mechanisms in Malaysia does not support adoption of RE technology and thus renewable energy technology is not commercially viable and unattractive.

Policy Barriers: This barrier encompasses political, institutional and regulatory conditions whereby with political wills and policy friendly environment, the government should lead by examples by engaging specialists in formulating more practical regulations, in moving forward the renewable energy.

Administrative Barriers: Involvement of too many organisations for administrative process, permitting procedures and maintenance activity resulting in coordination problem among the different authorities. The high administrative burden of achieving RE targets, with long delays in authorization and the absence of standardized access conditions, can dampened to progress of RE implementation. This is causing political risk on the part of investors and a consequent higher reluctance to invest in those environments

Socio-cultural barriers: Limited public awareness in terms of RE technologies; RE social benefit, RE environmental benefits along with availability of adequate cheap fuel energy resources discourage the uptake of $\mathrm{EE}$ initiatives among the citizens. EE investment is regarded as risky and costly [16].

\section{Energy Efficiency - moving forward}

The energy efficiency drives and renewable energy initiatives in Malaysia failed to meet the targeted energy saving set by the government and the results are still far behind when compared to the success rate recorded by other developed nations. As one of the latecomer from emerging nations, Malaysia suffers from several disadvantages as they attempt to catch-up with the technological leaders, but they can enjoy latecomer advantages, if appropriate strategies are formulated and executed. One of the key concepts is leapfrogging, whereby the latecomers absorb what the technological leaders have to offer and leap to a new environmentfriendly techno-economic paradigm. To facilitate such leap, the current intellectual-property-rights regimes need to evolve to one that fosters technology diffusion and greater use of intellectual property [17]. Comparison between barriers towards successful implementation of energy efficiency and renewable energy in Malaysia with other developed nations shows consistent results. This shows that the barriers are common issues and are not only isolated to Malaysia. Acknowledging the weaknesses and barriers encountered under previous initiatives and programmes, Malaysian government had launched National Energy Efficiency Action plan for implementation period of 2016-2025 (NEEAP) with 4 strategic thrusts namely Implementation of EE Plan, Strengthen Institutional 
Framework, Capacity Development and Training, Establishment of Sustainable Funding Mechanism and Promotion of Private Sector Investment in Energy Efficiency Initiatives. Three key initiatives under NEEAP include programmes for equipment, industrial and Buildings are similar with similar initiatives by other developed countries [13].

The program initiatives planned under NEEAP are not specific to Malaysian contexts, they are similar to those already implemented in other countries. The relevant authorities should not work in isolation. Knowledge sharing with others on weaknesses and strengths of their energy efficiency initiatives is the key in fine tuning Malaysia own initiatives under NEEAP. Findings from scientific scholarly researches by locals and international researchers could be beneficial in formulating practical EE regulations, initiatives and programmes.

Possible improvement to NEEAP is by going back to basic with clearly defined and easy to understand policies, initiatives and methodologies. Government should set reasonable and attainable energy efficiency performance target based on current resources and capabilities. Initiatives for energy efficiency, energy conservation and renewable energy to be treated separately, planned and monitored by different authorities to avoid overlapping of responsibilities. However, the end results can still be combined to get a holistic picture of the overall energy performance. Intangible initiatives for energy conservation to be gauged based on success rate of long term educational and awareness campaigns as part of government programme to make the citizens as smart energy consumers [18].

Government may employ more stringent tiered energy tariff for all sectors to benefit low energy consumers and to heavily burden those who practice unsustainable high energy consumption. Taxes on all energy consumption can reduce energy use across the board while reducing a broader array of environmental consequences arising from energy production. Tiered energy tax and carbon tax to be treated separately and to be combined with incentives and rebates to offset any monetary expenditure and investment for energy efficiency. All submissions to different authorities related to energy requirements can be part of planning approval and building permit and to be parked under current One Stop Centre of the local municipality [19]. This will avoid lengthy procedures, delay in approval and remove unnecessary charges.

The Initiatives under equipment programme is designed to promote the use of 5-star rated appliances and setting minimum energy performance standards (MEPS). Most consumers are poorly informed of the savings of energy efficient products as they may choose cheaper products which consumed more energy. The governments and NGOs should put effort to reduce the complexity in choosing these products by displaying ecolabels complying with regulated standards that make differences in energy efficiency to ease research before making any purchase. Conventional products should be slowly phased out and replaced with energy efficient products to be made available at affordable price due to volume increase [20].

Initiatives under building Programme require energy audits and energy management for existing and new buildings to incorporate energy efficient building design. It offers the largest opportunity towards energy efficiency as every citizen need homes, work places, commercial outlets, sport and entertainment centre in their daily life. Every building should be fitted with energy efficient equipments and fittings. Energy efficiency requirements can be part of building by-laws with mandatory compliance by new buildings and retrofitted buildings. Energy tax \& rebate may encourage more energy retrofit to building. Passive solar design should be encouraged as it is more effective than energy retrofits [21]. Employing step by step approach combining various levels of energy efficiency measures in buildings may offer better choices to consumers and greater understanding on mechanism in achieving the final targets. For example, combining the four main aspects for energy efficiency in a building include first and foremost the nearly zero energy passive building design before actual construction, secondly the usage of low energy building materials during its construction, thirdly use of energy efficient equipments for low operational energy requirement and lastly integration of renewable energy technologies for various applications [22].

Initiatives under industrial programme would involve energy audits and management for industrial sectors including promotion of co-generation of energy. Industrial programme initiative merit a different approach as the requirements are more complex. The government may consider enforcing a different set of mandatory regulations, by-laws and requirements specific for the industrial sector as they are among the largest consumer of energy and the biggest producer of gas emission. Co-generation of renewable power large industry operations may help reduce energy consumption [23].

Transportation industry is the highest emission of carbon as most vehicles run on fossil fuel. Energy conservation initiatives is best suited for adoption in transportation sector, simple act of walking, riding bicycle, car pooling, taking public transport can reduce energy consumption and carbon mission. Advance communication technology can also contribute towards energy conservation, many transactions can be done online reducing the need of travelling and the option to work from homes.

Ultimately, the government must be committed in their long-term energy efficiency initiatives as they are fully responsible to provide the necessary infrastructure to support system the sustainable eco system of the energy sector to benefit its citizens. Close relationship between the government with private sectors and NGOs may produce better results. 


\section{References}

1. H. Herring, Energy Efficiency-A Critical Review Energy vol. 31 pp 10-20 (2006)

2. IRENA, Synergies between Renewable Energy and Energy Efficiency (2017)

3. IEA, Renewables 2017 Analysis and Forecasts to 2022, (2017)

4. Suruhanjaya Tenaga, Laporan Tahunan 2011, (2011)

5. IEA, World Energy Outlook, vol 30 (2017)

6. O. Zehner, Green Technology, pp 427 - 432 (2011)

7. APEC, Peer Review on Energy Efficiency in Malaysia (2011)

8. R. Saidur. Energy Consumption, Energy Savings and Emission Analysis in Malaysia Office Buildings, Energy Policy vol 37, pp 4104-4113 (2009)

9. M. Diesendorf, Green House Solutions with Sustainable Energy, vol 86 (2007)

10. A. Al-Mofleh, S. Taib, M. A. Mujeebu, W. Salah, Analysis of Sectoral Energy Conservation in Malaysia, Energy, vol 34, pp 733-739 (2009)

11. I. Sartori, A.G. Hestnes. Energy Use in the Life Cycle of Conventional and Low-Energy Buildings: $A$ review article, Energy and Buildings, vol 39 (2007)

12. T. Ramesh, R. Prakash, K. Kshukla, Life Cycle Energy Analysis of Buildings: An overview, Energy and Buildings, vol 42 (2010)

13. KETTHA, "National Energy Efficiency Action Plan", (2015)

14. K. Lo, M. Y. Wang, Energy Conservation in China's Twelfth Five-Year Plan Period: Continuation or Paradigm Shift? Renewable and Sustainable Energy Review, vol 18, pp 499-507 (2013)

15. A. Vaughan, Renewables made up half of net electricity Capacity (2016)

16. A. H. Shamsuddin, Development of renewable energy in Malaysia strategic initiatives for carbon reduction in the power generation sector, Procedia Engineering, vol 49 pp 384-391 (2012)

17. Investopia, Top 25 Developed and Developing Countries (2016)

18. S. Yusoff, R. Kardooni, Barriers and challenges for developing $R E$ policy in Malaysia, International Conference on Future Environment and Energy IPCBEE, vol 28 (2012)

19. J. Dawson, A guide for effective energy saving, Renewable Energy World. vol 19 (2016)

20. P. Leslie, J. Pearce, R. Harrap, S. Daniel, The application of smartphone technology to economic and environmental analysis of building energy conservation strategies, International Journal of Sustainable Energy, vol 31, pp 295-311 (2012)

21. Commission, California Energy. Consumer Energy Center - Incandescent, LED, Fluorescent, Compact Fluorescent and Halogen Bulbs (2012)

22. A. Chel, G. Kaushik, Renewable Energy Technologied for Sustainable Development of Energy Efficient Building, Alexandria Engineering Journal (2017)
23. S. Breukers, E. Heiskanen, Interaction schemes for successful demand-side management. Deliverable 5 of the Changing Behaviour project, (2009) 